\title{
UMA ANÁLISE DA FERRAMENTA ALICE NO ENSINO DA LÓGICA DE PROGRAMAÇÃO
}

\author{
AN ANALYSIS OF ALICE TOOL IN TEACHING LOGIC \\ PROGRAMMING
}

\author{
Márcia Antônia Dias Catunda* \\ Mayumi Passos Lopes** \\ José Aires de Castro Filho***
}

\begin{abstract}
Resumo: O presente artigo avalia a ferramenta Alice como forma de incentivar os alunos a obterem êxito na disciplina de Lógica de Programação nos cursos técnicos em Informática de escolas profissionais do município de Fortaleza. A escolha de tal software educativo se deu pelo fato de o ambiente ser de fácil utilização, atraindo o aluno por meio de animações e interações entre personagens e objetos, lembrando muito os jogos de videogames, algo presente no cotidiano do aluno. Diante disso, busca-se mostrar se essa ferramenta de fato traz resultados positivos para o ensino de Lógica de Programação, considerada uma disciplina difícil por muitos estudantes. A metodologia utilizada foi a pesquisa descritiva, com análise dos dados feita com alunos de uma escola de Fortaleza. Com base nos resultados do trabalho, verificamos que, através do uso da ferramenta Alice, houve uma melhora nas notas dessa disciplina e grande entusiasmo por essa nova forma de ensinar e de aprender lógica de programação.
\end{abstract}

Palavras-chave: Alice. Lógica de Programação. Software educativo. Interação.

Abstract: This article evaluates the Alice tool as a way to encourage students to succeed in the discipline of Programming Logic in technical courses in Informatics at professional schools in the city of Fortaleza. The choice of such educational software was due to the fact that the environment is easy to use, attracting the student through animations and interactions between characters and objects, very reminiscent of video games, something present in the student's daily life. Therefore, we seek to show whether this tool actually brings positive results for the teaching of programming logic, which is considered a difficult discipline by many students. The methodology used was descriptive research, with data analysis made with students of a choice in Fortaleza. Based on the results of the work, we verified that, through the use of the Alice tool, there was an improvement in the grades of this discipline and we noticed a great enthusiasm for this new way of teaching and learning programming logic.

Keywords: Alice. Programming Logic. Educational Software. Interaction.

\footnotetext{
* Jornalista formada pela Universidade Federal do Ceará (UFC), especialista em Ensino da Língua Portuguesa (UECE), mestra em Informática Educativa (UECE), com experiência em assessoria de imprensa, revista e portal. No meio acadêmico, foi bolsista de Iniciação Científica, Monitora Institucional e Pesquisadora Voluntária. Tem experiência como tutora EAD na Secretaria de Educação do Estado do Ceará (SEDUC) e na Escola de Saúde Pública do Ceará. Atualmente é tutora EAD na UNIEDUCAR, professora do curso de Dicção e Oratória do Senac, professora de Português Instrumental da Grau Técnico, professora das disciplinas de Didática do Ensino Superior e Metodologia Científica da UNICORP Fortaleza e revisora de periódicos na Escola de Saúde Pública do Ceará. E-mail: catundamarcia@gmail.com

** Mestre em Informática Educativa - UECE, especialista em Gestão e Coordenação Pedagógica pela Faculdade 7 de Setembro (2014) e Graduada em Letras - Português pela Universidade Estadual Vale do Acaraú (2009). Atualmente exerce o cargo de Diretora Escolar na EEEP Mário Alencar. Possui experiência na área de Educação e na área de Língua Portuguesa, com ênfase em Educação, Literatura, Gramática, Interpretação, Produção e Revisão Textual. E-mail: mayumilopess@ gmail.com

*** Possui graduação em Engenharia Civil pela Universidade Federal do Ceará (1988), mestrado em Psicologia (Psicologia Cognitiva) pela Universidade Federal de Pernambuco (1992) e doutorado em Mathematics Education - University Of Texas At Austin (2000). Atualmente é professor Titular da Universidade Federal do Ceará, atuando no curso de Bacharelado em Sistemas e Mídias Digitais do Instituto Universidade Virtual e no Programa de Pós-Graduação em Educação Brasileira da Faculdade de Educação. É Líder do Grupo de Pesquisa e Produção em Ambientes Interativos e Objetos de Aprendizagem (PROATIVA) desde 2004. Atua principalmente nos seguintes temas: Informática Educativa e Educação Matemática. E-mail: aires@ virtual.ufc.br
} 


\section{Introdução}

O homem transita culturalmente mediado pelas tecnologias que lhe são contemporâneas. Elas transformam suas maneiras de pensar, sentir, agir. Mudam também suas formas de se comunicar e de adquirir conhecimentos (KENSKI, 2006). Ensinar tecnologia contempla questões relacionadas ao pensamento sistematizado, fundamentos da eletrônica, mecânica, informática e da mecatrônica de uma forma prática e acessível, o qual tem a sua base no ensino das ciências.

A necessidade do presente estudo se deu pelo fato de o sistema educacional brasileiro possuir um grande número de estudantes que iniciam um curso técnico de Informática e de Redes de Computadores, mas apresentam inúmeras dificuldades para obterem êxito em cumprir as exigências curriculares. Tal dificuldade é verificada especialmente na disciplina de Lógica de Programação, que acaba ganhando destaque nos cursos de Informática por ser pré-requisito para as disciplinas posteriores, que abrangem desenvolvimento de software, exigindo que o estudante aprenda o que é apresentado para que obtenha aprovação nas disciplinas subsequentes.

Ao mesmo tempo em que tal conteúdo merece destaque no decorrer do curso, ele também merece maiores cuidados por parte dos educadores que o ministram, já que muitos educandos encontram dificuldades para entender a lógica computacional.

De acordo com Rodrigues (2002), a disciplina tem um dos maiores indicadores de reprovação em todos os estabelecimentos de ensino brasileiro e esta realidade tem produzido uma razão para cuidado e reflexão por parte dos educadores. A evasão dos alunos que não completam o curso técnico de Informática se configura como um dos grandes problemas que ocorrem em instituições públicas e particulares.

Por conta da dificuldade apresentada, pensou-se no software Alice para minimizar tal fenômeno, ferramenta que tem como propósito desenvolver programas interativos, criando ambientes gráficos $2 \mathrm{D}$ ou mesmo em $3 \mathrm{D}$, fazendo com que o aluno possa usar toda a sua criatividade para desenvolver novas ideias de animações. Alice utiliza a lógica de programação para que suas funcionalidades possam surtir efeito positivo, assim, decidimos utilizar essa ferramenta para que sejam repassados aos alunos não apenas conceitos teóricos de como funciona a lógica de programação, mas também a vivência. Assim os discentes perceberão de forma prática os efeitos adquiridos nas aulas de lógica através do uso do software.

Diante do exposto, busca-se neste trabalho analisar os efeitos e resultados do uso da ferramenta Alice no ensino da disciplina de Lógica de Programação, a qual é considerada complexa por muitos estudantes. Busca-se ainda com esse software avaliar se o uso da ferramenta facilita o aprendizado dos estudantes acerca dos assuntos relacionados à matéria, a fim de deixar o ensino menos confuso e complexo.

O ambiente disponibiliza o que é denominado World (mundo), em que as interações acontecem. A partir de elementos pré-programados que acompanham a ferramenta, é possível criar histórias seguindo uma construção lógica. Cada objeto possui características próprias com classes básicas, que podem ser modificadas e organizadas à maneira do aluno. Trata-se de uma aplicação de uma linguagem orientada a objetos aos moldes das linguagens mais conhecidas como Java e $\mathrm{C}^{++}$, por exemplo.

Dessa forma, este trabalho tem por objetivo a avaliação do uso da ferramenta Alice para o ensino da Lógica de Programação.

Alice é um software que ajuda na construção de mundos virtuais $3 \mathrm{D}$, os quais possuem na composição objetos gráficos com comportamentos associados que alteram 
com o tempo. Objetos em Alice podem mover, girar, mudar de cor, emitir sons, reagir ao mouse e teclado, entre outras atividades.

As primeiras versões da ferramenta permitiam a construção de mundos virtuais por meio da utilização da linguagem Alice, baseada em Python. Atualmente, é uma ferramenta de autoria, com um ambiente de desenvolvimento embutido, na qual o usuário pode construir mundos virtuais por meio da interface gráfica da ferramenta ou usando a linguagem Alice.

É importante investir no ensino de Lógica de Programação, pois nossa sociedade está cada vez mais adepta aos meios tecnológicos A inserção dos computadores na educação foi uma espécie de revolução, pois o computador passou a servir também como tutor eletrônico com a utilização dos diversos softwares educacionais que começaram a surgir. $\mathrm{O}$ computador se tornou extremamente útil na educação, além de outras funcionalidades, e sua aceitação nessa área se deu pelo potencial metodológico que ele agregava e agrega até hoje (NASCIMENTO, 2015, p. 21).

Nas seções a seguir, será feita uma abordagem teórica acerca das linguagens de programação e seus paradigmas; posteriormente, um detalhamento acerca da ferramenta Alice; na seção seguinte, a descrição da metodologia utilizada no trabalho das atividades realizadas; os resultados e as discussões no tópico posterior, finalizando-se o artigo com a conclusão.

\section{Linguagens de programação e paradigmas}

A Lógica de Programação constitui-se como uma disciplina integrante da proposta curricular dos cursos técnicos de Informática e de Redes de Computadores das escolas estaduais de educação profissional do Ceará e envolve, em linhas gerais, o estudo da programação de computadores.

A aprendizagem da lógica de programação está conectada com algoritmos coerentes e válidos. Algoritmos são sequências lógicas para resolver determinados problemas. A linguagem de programação é utilizada para traduzir um algoritmo de forma que o computador possa executá-lo. Assim como o pensamento humano pode ser expresso em diversas línguas, o algoritmo pode ser escrito em várias linguagens de programação.

Os mundos programáveis são métodos usados para tornar mais fácil o aprendizado da programação e inspirados na linguagem Logo (PAPERT, 1980). Esses ambientes, geralmente, excluem os pormenores que não são relevantes para os conceitos que estão sendo aprendidos. Objetivam inserir os estudantes no universo de um agente uma tartaruga ou um robô - para que se sintam protagonistas nessa condução, tornando mais fácil dessa maneira a elaboração dos padrões intelectuais dos conceitos que estão a estudar (BUCK; STUCKI, 2001).

A linguagem de programação pode ser definida como um conjunto de regras e comandos com sintaxe e semântica próprias, utilizadas pelo programador para traduzir os algoritmos, e tem como objetivo enviar comandos para serem executados pelo processador e pela memória do computador. A proximidade com a linguagem humana define o nível da linguagem de programação. As linguagens de programação são classificadas em linguagens de baixo nível e de alto nível. Linguagens de baixo nível se caracterizam por se aproximarem muito das instruções usadas pela CPU. As instruções de máquina são representadas por bits na memória. Linguagens de alto nível são linguagens com um nível de abstração relativamente elevado, longe do código de máquina e mais próximo da linguagem humana. 
Desse modo, as linguagens de alto nível não estão diretamente relacionadas à arquitetura do computador. O programador de uma linguagem de alto nível não precisa conhecer características do processador, como instruções e registradores, pois essas características são abstraídas na linguagem de alto nível.

O ensino de Lógica de Programação para crianças normalmente se dá através de métodos lúdicos, nos quais elas aprendem se divertindo com softwares dinâmicos, coloridos e de fácil compreensão (NASCIMENTO, 2015, p. 22).

Jenkins (2002) cita as várias causas do insucesso generalizado em disciplinas de programação, como: o baixo nível de abstração, a falta de competências de resolução de problemas, a inadequação dos métodos pedagógicos aos estilos de aprendizagem dos alunos, entre outros; e afirma que as linguagens de programação possuem sintaxes adequadas para profissionais, mas não para aprendizes inexperientes.

Gomes, Henriques e Mendes (2008) comentam que o desinteresse pode acontecer por dificuldades de interpretação ou por os alunos se sentirem demasiados ansiosos para começar a codificar sem antes compreender os dados do problema, dificultando a fase seguinte, a construção do algoritmo. A dificuldade de empregar o raciocínio lógico, afirmam Barros, Delgado e Machion (2004), também gera um ambiente desmotivante, justificando a redução de alunos através de uma possível evasão ou reprovação na disciplina. Por isso, a ferramenta Alice surge como uma solução para esse problema.

São imensos os recursos que hoje são disponibilizados na internet e que podem ajudar no aprendizado de programação por parte da criançada. Elas podem aprender através de jogos nos quais elas mesmas escolhem o tema de seu interesse. É muito importante que, ao mesmo tempo em que brinquem, as crianças estejam aprendendo algo, principalmente quando relacionado à tecnologia, pois em nossa volta estamos repletos dela (NASCIMENTO, 2015, p. 22).

Na seção posterior, será feita uma descrição da ferramenta Alice, evidenciandose suas características, o tipo de linguagem utilizada e a forma como o software se apresenta.

\section{A ferramenta}

Alice é uma plataforma que introduz aos estudantes o conceito da lógica de programação, utilizando linguagem e recursos simples que facilitam e que apoiam os estudantes no aprendizado, sendo muito utilizada na criação de desenhos gráficos e em jogos que utilizam recursos em 2D e 3D, o que faz aumentar o interesse no aprendizado de conceitos via essa ferramenta.

Essa plataforma foi desenvolvida para que suas instruções fossem similares às de linguagens como Java ${ }^{1}$ e $\mathrm{C}++^{2}$. Outro fato importante de Alice é que, no momento da adição das instruções, torna-se possível visualizar os efeitos realizados por cada comando executado, assim o aluno descreve o código e ao mesmo tempo vê os dados sofrendo alteração na tela. Dessa forma, o aluno vai pouco a pouco ganhando conhecimentos sobre programação, sem se preocupar com detalhes que possam distanciá-lo de uma linguagem de programação.

A plataforma Alice contém um ambiente com cinco sessões: a primeira é constituída pelo cenário no qual é mostrado o resultado gráfico desenvolvido pelos

\footnotetext{
${ }^{1}$ Java é uma linguagem de programação - Deiltel (www.devmedia.com.br).

${ }^{2} \mathrm{O} \mathrm{C}++$ é uma linguagem de uso geral - Deiltel.
} 
alunos; a segunda é constituída pela área referente a "árvores de objetos", na qual são mostrados detalhes de todas as ferramentas que estão sendo utilizadas naquele momento pelo desenvolvedor. Na terceira área, ocorre o detalhamento do objeto o qual está sendo desenvolvido. Essa sessão consiste em mostrar suas propriedades, métodos e funções. A quarta área, chamada de área de edição, é o local em que a programação dos objetos acontece. Nessa sessão, é criado um roteiro de ações que norteiam a aplicação e o que está sendo desenvolvido nela. Por fim, temos a última sessão, chamada de "área de eventos", na qual encontramos os componentes que podemos "arrastar" e "criar" as aplicações visuais necessárias no projeto.

A Figura 1 mostra detalhes importantes da ferramenta do nosso estudo, layout e apresentação física da tela inicial:

Figura 1 - Tela inicial do ambiente Alice

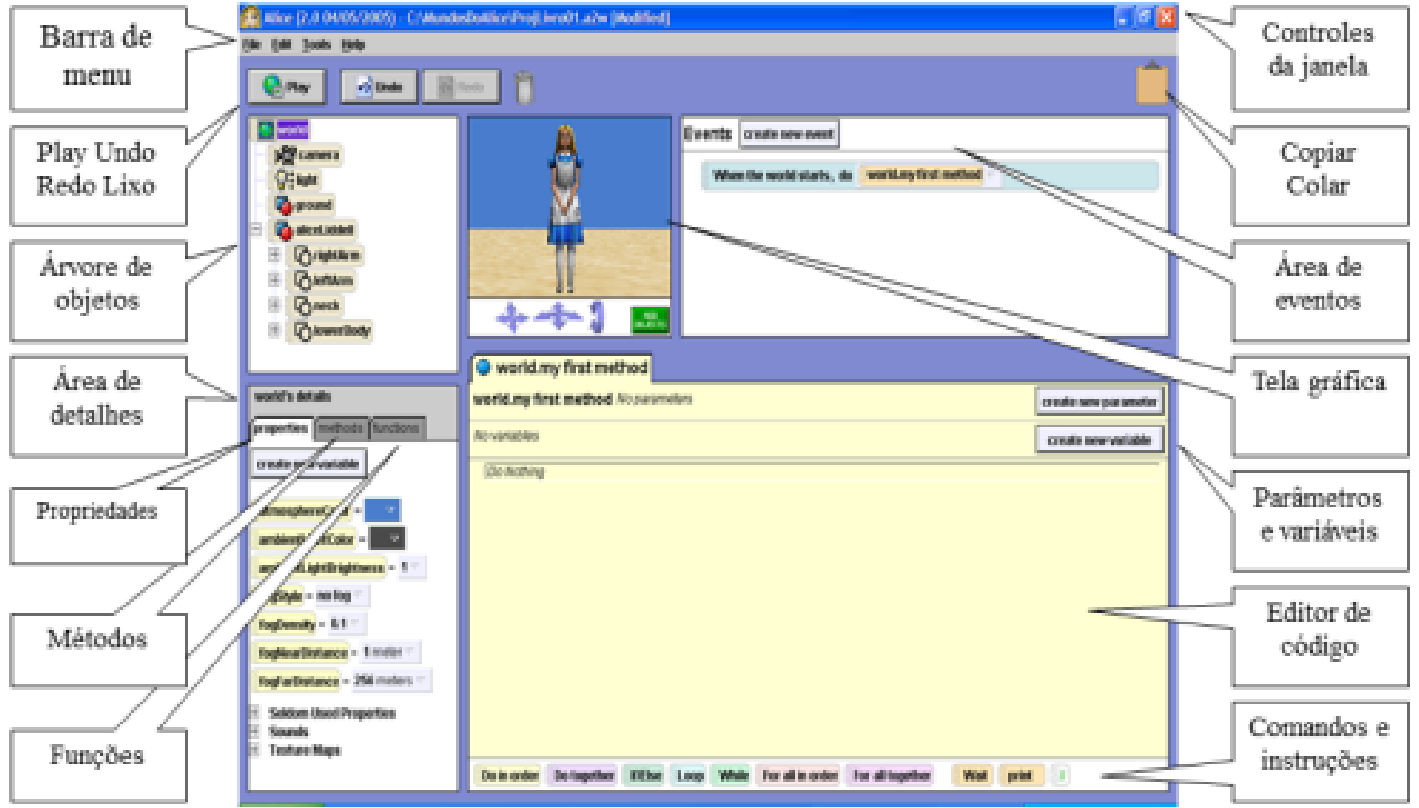

Fonte: http://www.alice.org. Acesso em: 05 nov. 2017.

Alice é uma linguagem de programação funcional, concebida pelo Laboratório de Programação de Sistemas da Universidade do Sarre. Trata-se de um software livre que tem entre suas características compilação just in time e código nativo para a arquitetura X86 (CONWAY, 1997).

A ferramenta Alice é um software que solicita um comando lógico e, através deste, consegue realizar ações advindas de imagens. O aluno consegue visualizar de forma rápida e clara quais ações foram tomadas de acordo com o comando ou algoritmo executado.

\section{Trabalhos relacionados}

A Alice é uma ferramenta considerada popular pelos alunos de Informática e, por isso, já foi objeto de estudo de vários pesquisadores. Gross, Christmann e Martini (2009) avaliam o ensino de Lógica de Programação aos alunos do Ensino Médio com o uso da Alice e descobriram que esse tipo de software é relevante no ensino e na aprendizagem. Já Silva, Neto, Barbosa, Alves e Rodrigues (2014) fazem uma análise 
geral de várias ferramentas, mas dentre elas destacam a Alice. Eles afirmam que, "entre seus pontos positivos, permite a aprendizagem de programação de maneira divertida, ajuda na materialização de conceitos abstratos, introduz conceitos de orientação a objetos como (objeto, classe e métodos) e por fim contribui no desenvolvimento do raciocínio lógico" (SILVA, NETO, BARBOSA, ALVES e RODRIGUES, 2014, p. 1470)

Alice também auxilia na aprendizagem de algoritmos, como revelam Raabe, Marques e Silva (2005). Porém, nem sempre a ferramenta consegue resolver todos os problemas de ensino e aprendizagem, como apontam Valaski e Paraiso (2012). Os pesquisadores concluíram que "os resultados obtidos mostraram que, a princípio, a utilização do Alice não contribuiu de forma significativa na aprovação de Programação I. Por outro lado, houve uma redução na evasão de alunos da disciplina". No tópico a seguir, discutiremos sobre a metodologia utilizada no decorrer da pesquisa.

\section{Metodologia}

Esta pesquisa foi desenvolvida por meio de questionário, "instrumento de coleta de dados constituído por uma série de perguntas que devem ser respondidas por escrito" (MARCONI; LAKATOS, 1999, p. 100), junto às turmas de $1^{\circ}$ e $2^{\circ}$ ano do Ensino Médio, na disciplina de Lógica de Programação das escolas profissionais José de Barcelos e Mário Alencar, ambas da cidade de Fortaleza, Ceará.

Foi escolhida a técnica múltipla escolha (perguntas fechadas, mas que apresentam uma série de possíveis respostas, abrangendo várias facetas do mesmo assunto), por ser facilmente tabulável e por proporcionar uma exploração em profundidade quase tão boa quanto a de perguntas abertas.

O instrumental foi aplicado a 160 alunos, no qual foi possível obter dados bastante relevantes, em termos de aprimoramento da disciplina, conhecimento mais aprofundado dos conceitos de lógica de programação, assim como um aumento na produtividade e qualidade dos algoritmos desenvolvidos.

A utilização da ferramenta foi abordada junto aos alunos no início do primeiro semestre de 2017, sendo necessário, a priori, laboratórios, em que todos os computadores tivessem instalada a ferramenta Alice. Para isso, as escolas disponibilizaram todas as condições necessárias.

Vale ressaltar que foi formado um grupo de seis alunos que assumiram o papel de monitores da disciplina, possibilitando, assim, uma melhor mediação e aproximação do restante da turma para o entendimento da disciplina. Tais alunos foram escolhidos devido à sua afinidade com a disciplina de Lógica de Programação.

No tópico a seguir, serão descritas as atividades realizadas.

\section{Descrição das atividades realizadas}

Elaboraram-se ambientes tridimensionais nos quais puderam ser realizadas determinadas atividades. Com os ambientes já montados, iniciaram-se as interações entre o cenário e os personagens nele inseridos. Os ambientes criados no Alice foram impressos e distribuídos aos alunos, que os utilizaram como materiais de estudo, bem como uma apostila também elaborada a partir dos ambientes desenvolvidos.

Os testes iniciais foram aplicados aos alunos de $2^{\circ}$ ano e, posteriormente, resolvemos antecipar os testes com os alunos de $1^{\circ}$ ano, pois constatamos que poderia 
ser uma experiência enriquecedora iniciar os estudos da lógica de programação já visualizando as mudanças que cada linha de código poderia implantar em cada cenário, uma vez que o software disponibiliza animações que serão programadas a partir de suas primeiras linhas de código.

\section{Resultados e discussões}

Por meio da tabulação das respostas dos questionários, observou-se, nessas situações, uma boa aceitação pelos alunos e uma melhoria de interesse e interação entre eles na sala de aula. As ferramentas que facilitam o ensino-aprendizagem orientam melhor as ações interdisciplinares futuras.

Para este relato de experiência, tomaram-se apenas as questões 2 e 7 (e seus subitens) dos testes avaliativos aplicados aos alunos com vistas a conhecer alguns aspectos importantes da experiência vivenciada com o uso da ferramenta Alice.

$\mathrm{Na}$ questão 2, buscou-se conhecer especificamente informações quanto à usabilidade da ferramenta. Os quesitos dessa questão consistiam de indagações quanto a:

- Facilidade de entender como funciona o programa (2.1);

- Facilidade de utilização de software quanto à manipulação dos objetos da biblioteca (2.2);

- Facilidade quanto à personalização dos objetos "personagens" (2.3);

- Facilidade quanto à programação, se complexa ou não (2.4);

- Avaliação global acerca da usabilidade do software (2.5).

Em síntese, numa avaliação global acerca da usabilidade do software, os sujeitos afirmam que estão de satisfeitos a muito satisfeitos em sua maioria, excetuando o que se propõe nos itens referentes à facilidade quanto à personalização dos objetos "personagens" e à programação, se complexa ou não, em que se identifica um número considerável na amostra de sujeitos pouco satisfeitos, como pode ser conferido na exposição do gráfico a seguir:

Gráfico 1 - Resultado da avaliação do software quanto aos aspectos de usabilidade

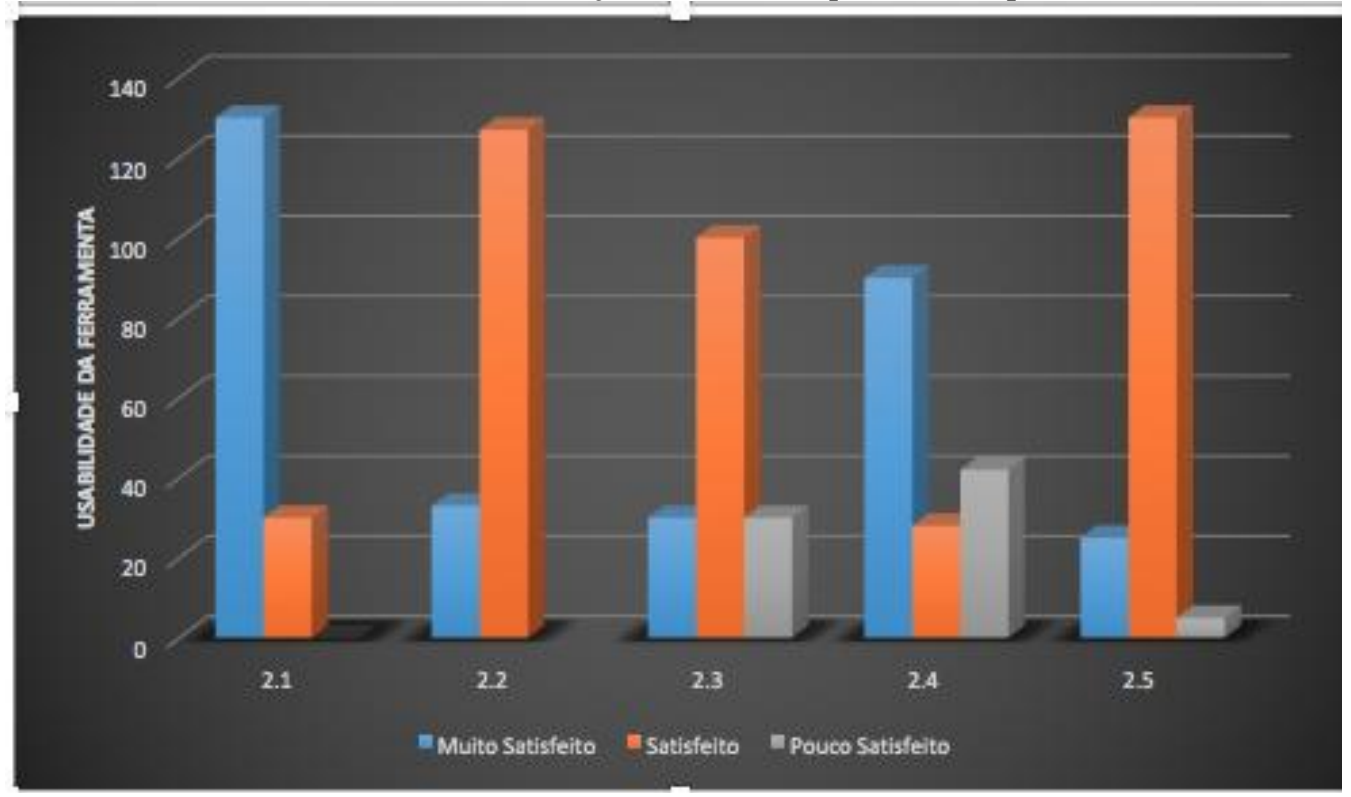

Fonte: Autoria própria

Assim, vale destacar o item 2.3, referente a objetos "personagens", em que $12,5 \%$ dos alunos responderam que estão pouco satisfeitos e mais de $60 \%$ estão 
satisfeitos. No item 2.4, sobre a facilidade em relação à programação, se era complexa no entendimento deles, $25 \%$ responderam que estão pouco satisfeitos nesse quesito e $50 \%$ estão satisfeitos. Já em relação à usabilidade, no item 2.5 , menos de $5 \%$ alegaram pouca satisfação, já $75 \%$ mencionaram que estão satisfeitos.

Convém destacar que o software em questão colabora com o desenvolvimento do contexto da disciplina e do seu conteúdo (Lógica de Programação e Programação Orientada a Objetos), proporciona a realização de experiências didáticas em ambientes com realidade virtual, entre outros aspectos, como a importância de programar em blocos e a importância geral do sistema na disciplina.

No que corresponde à segunda pergunta presente no questionário, que versa sobre a importância de um software dessa natureza em aulas para melhor aprendizagem da lógica de programação e de conteúdos específicos, quase todos os alunos atribuíram a todos os quesitos referência positiva quanto à contribuição em relação aos conteúdos curriculares destacados na consulta, sendo que $3 \%$ deles negativaram.

Gráfico 2 - Resultado da avaliação do software quanto a sua importância

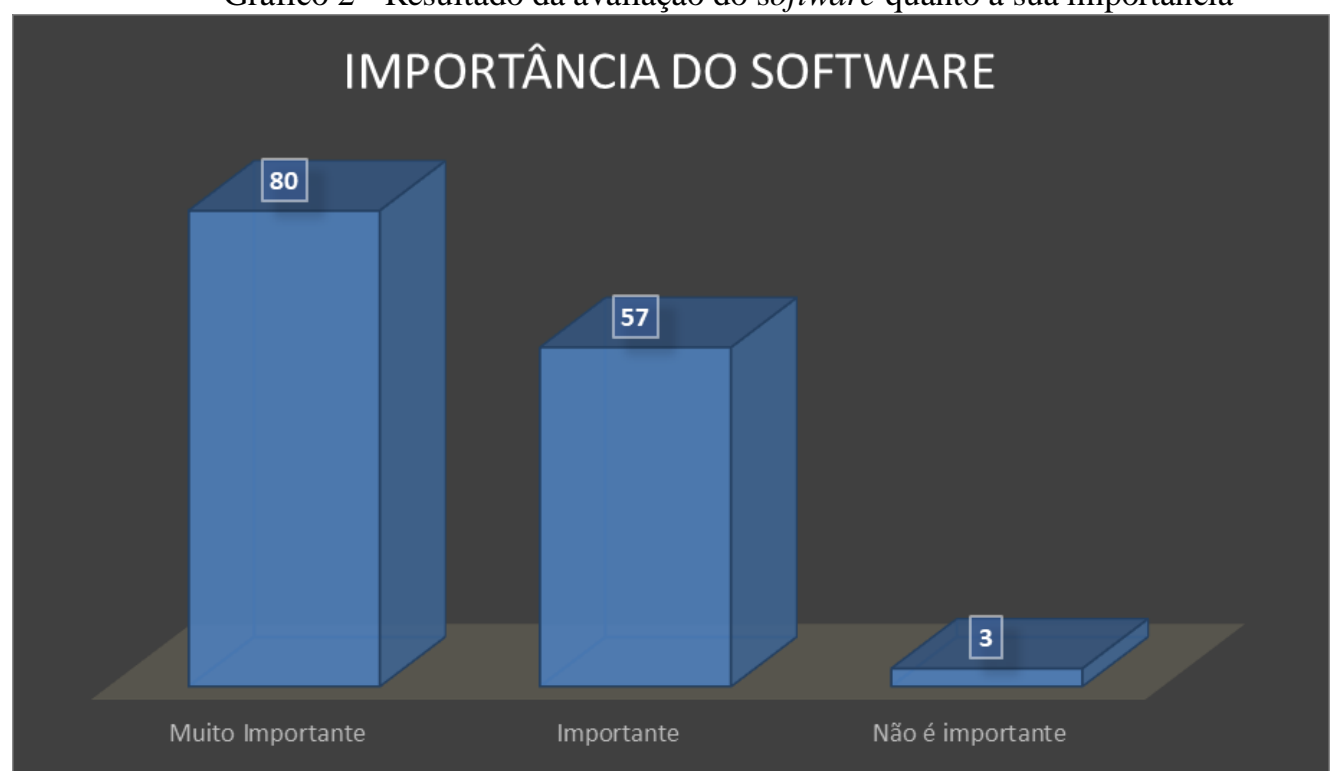

Fonte: Autoria própria.

Ao finalizarmos a intervenção-investigação, foram discutidos os resultados e as aprendizagens construídas com os alunos. Comparando esses resultados com turmas em aulas mais tradicionais, podemos constatar um aumento percentual em torno de $10 \%$ nas notas na média dos alunos, contudo, no aspecto de estímulo ao curso, realmente os resultados são muito mais significativos.

A avaliação do usuário sobre seu desenvolvimento/desempenho em programação usando Alice foi investigado a partir das questões que versam sobre:

- $\quad$ 7.1 Qual seu nível de programação em Java antes da disciplina?;

- $\quad 7.2$ Qual sua experiência em programação orientada a objetos antes da disciplina?;

- $\quad$ 7.3 Qual seu nível de programação em Java depois da disciplina?;

- $\quad$ 7.4 Qual sua experiência em programação orientada a objetos depois da disciplina?

O gráfico organizado abaixo mostra as opiniões dos alunos em relação a seus conhecimentos ao iniciarem a experiência da qual participaram. Percebemos que o nível de conhecimentos prévios em lógica de programação se traduz em larga escala de 
iniciante a mais experiente, porém este último não teve pontuação como os níveis iniciante e intermediário, sendo praticamente nulo.

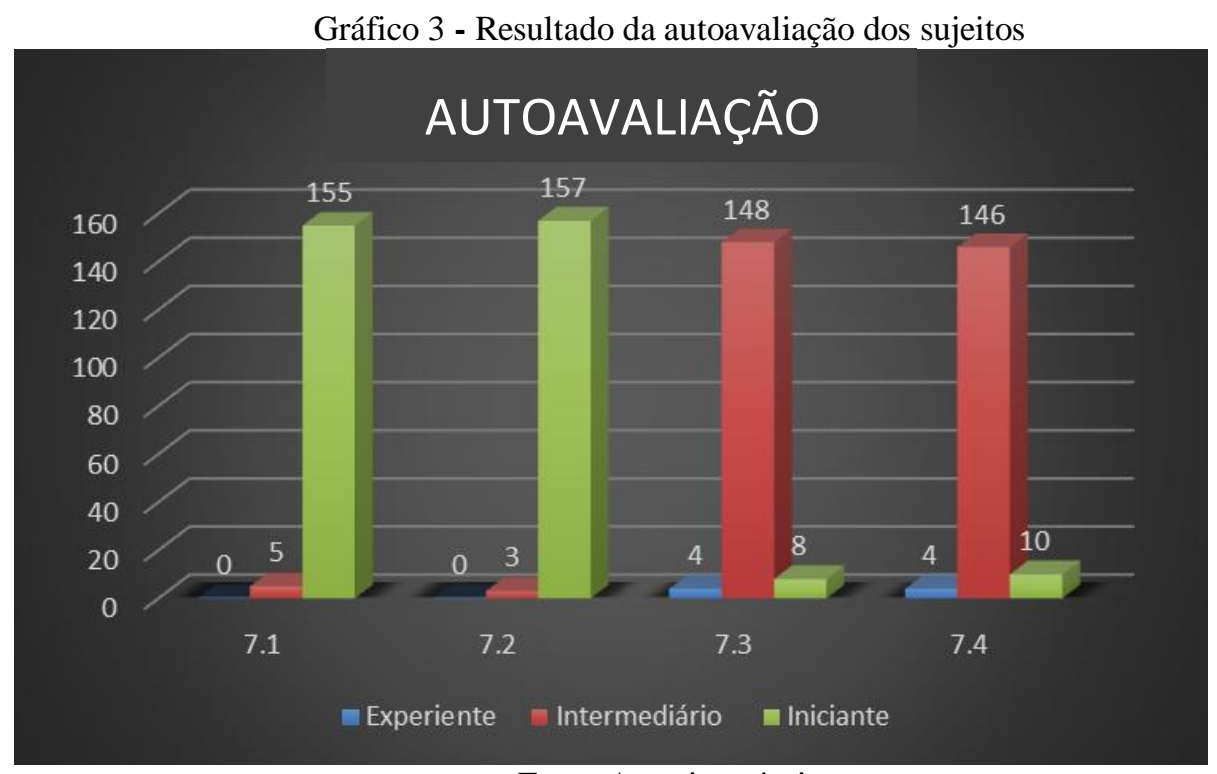

Fonte:Autoria própria

Sendo assim, percebe-se pelo gráfico que, nos itens 7.1 e 7.2, prevalecem os níveis iniciante e intermediário; já nos itens 7.3 e 7.4, a quantidade de experientes é de 4 alunos, o que corresponde a 2,5\% apenas do total de alunos envolvidos na pesquisa. Portanto, os dados de nível iniciante e intermediário são os que predominam com pontuação quase máxima, o que reforça o que já foi mencionado anteriormente.

Diante da ausência de conhecimentos prévios, lidamos com alunos que não detinham conhecimento do conteúdo trabalhado e que vivenciaram experiências significativas de aprendizagem. Como observado na implementação das atividadesintervenção, os alunos apresentam boa aceitação da ferramenta e esta desperta o interesse deles pela lógica, uma vez que foca na criação de jogos e animações, que são mais lúdicos e prendem mais a sua atenção, permanecendo o foco no conteúdo da lógica para sua criação.

\section{Considerações finais}

Com base nos resultados do trabalho, verificamos que, através do uso da ferramenta Alice, houve uma melhora nas notas da disciplina Lógica de Programação e grande entusiasmo por essa nova forma de ensinar e de aprender lógica de programação.

Os alunos de $1^{\circ}$ e $2^{\circ}$ anos que cursam essa disciplina evidenciaram, através de suas respostas aos questionários, o quão importante foi para eles poder desenvolver de forma prática os seus próprios objetos de estudo, com a utilização da ferramenta Alice.

Essa ferramenta nos parece importante de ser considerada nos planos de curso e de ação, já que se mostra como fundamental e necessária para uma boa aprendizagem dos alunos em cursos que contemplam tal conteúdo, como é o caso do Técnico em Informática e Redes de Computadores.

A partir dessas observações, pode-se concluir que o ensino de Lógica de Programação para crianças com o uso da ferramenta Alice permite que os estudantes pensem criticamente como se situar no momento de buscar alternativas para resolver problemas, permitindo dessa forma que eles cheguem aos seus objetivos. 


\section{Referências}

COOPER, Stephen; DANN, Wanda; PAUSCH, Randy. Teaching Objects-first In Introductory Computer Science. SIGCSE, 2003. 5p.

CONWAY, Mathew J. Alice: Easy-to-Learn 3D Scripting for Novices. Dissertação de $\mathrm{PhD}, 1997$. Estados Unidos. 242 p.

DANN, Wanda P.; COOPER, Stephen; PAUSCH, Randy. Learning to Program with Alice. Estados Unidos: Prentece Hall, 2005. 375 p.

GOMES, A.; HENRIQUES, J.; MENDES, A. J. (2008). Uma proposta para ajudar alunos com dificuldades na aprendizagem inicial de programação de computadores. Disponível em: http://goo.g1/DGLXh. Acesso em: jun. 2013.

GROSS, Paulo César Roque; CHRISTMANN, Felipe; MARTINI, Alfio. Desenvolvendo Lógica para Programação com o Alice. X SALÃO DE INICIAÇÃO CIENTÍFICA, Anais [...], PUCRS, 2009.

JENKINS, T. (2002). On the difficulty of learning to program. Disponível em: http://www.ics.heacademy.ac.uk/Events/conf2002/tjenkins.pdf. Acesso em: jun. 2013.

NASCIMENTO, Cledison da Silva. Introdução ao ensino de Lógica de Programação para crianças do Ensino Fundamental com a ferramenta Scratch. Rorainópolis, RR. dez. 2015.

RAABE, André Luís Alice; SILVA, Júlia Marques Carvalho. Um ambiente para atendimento as dificuldades de aprendizagem de algoritmos. In: XXV CONGRESSO DA SOCIEDADE BRASILEIRA DA COMPUTAÇÃO. Anais [...], 2005.

RODRIGUES, M. C. (2002). Como ensinar Programação?. Informática - Boletim Informativo. Canoas, RS, Ano I, n. 01, ULBRA. .

SILVA, Eraylson Galdino; BARBOSA, Aline F.; NETO, Sebastião R. S.; LOPES, Renato H. O.; RODRIGUES, Ariane N. Análise de ferramentas para o ensino de Computação na Educação Básica. In: XXXIV CONGRESSO DA SOCIEDADE BRASILEIRA DA COMPUTAÇÃO - CSBC, Anais [...], 2014.

VALASKI, Joselaine; PARAISO, Emerson Cabrera. Limitações da utilização do Alice no ensino de Programação para alunos de graduação. In: $23^{\circ}$ SIMPÓSIO BRASILEIRO DE INFORMÁTICA NA EDUCAÇÃO (SBIE 2012), Anais [...], Rio de Janeiro. ISSN 2316-6533.

Recebido em 20 de fevereiro de 2020

Aceito em 31 de maio de 2020 